\title{
Aspectos ultraestruturais de hemócitos de Biomphalaria glabrata Say (1818) (Gastropoda: Planorbidae) analisados sob microscopia eletrônica de transmissão
}

Marco Antonio Vasconcelos SANTOS ${ }^{1}$, José Antonio Picanço DINIZ²

RESUMO

Os hemócitos do caramujo Biomphalaria glabrata, um importante transmissor do trematódeo Schistosoma mansoni no Brasil, foram coletados de especimens na região Bragantina, localizada a oeste do estado do Pará. Os hemócitos foram examinados por meio de microscopia eletrônica de transmissão. As células foram fixadas pelo método de rotina com o uso do tampão PHEM (PIPES, HEPES, EGTA e Magnésio). Foram descritos os aspectos ultra-estruturais celulares como inclusões citoplasmáticas limitadas por membranas, mitocôndrias, retículos endoplasmáticos e outros. As observaçóes mostram que esse tampão possui a propriedade de preservação do citoesqueleto celular, apresentando bons resultados na preservação das estruturas dos hemócitos e suas organelas.

PALAVRAS-CHAVE: Mollusca; células sanguíneas; Pará; esquistossomose; tampão PHEM

\section{Ultrastructural aspects of hemocytes from Biomphalaria glabrata Say (1818) (Gastropoda: Planorbidae) analysed with transmission eletronic microscopy}

ABSTRACT

The blood cells of the pulmonate snail Biomphalaria glabrata from the region of Bragantina in the state of Pará, an important vector of the trematode Schistosoma mansoni in Brazil, were collected and fixed by routine method with PHEM buffer and examined with transmission electron microscopy. Ultrastructural cellular aspects like cytoplasmic inclusions, mitochondrion, vesicles and others organelles are described. The buffer used resulted in good preservations of the hemocytes and their organelles.

KEY WORDS: Mollusca; blood cells; Pará, schistossomosis; PHEM buffer

1 Instituto Evandro Chagas. E-mail: marcoantonio@iec.pa.gov.br

${ }^{2}$ Instituto Evandro Chagas. E-mail: joseantonio@iec.pa.gov.br 


\section{INTRODUÇÃO}

Os hemócitos são células em suspensão na hemolinfa de moluscos que atuam no sistema de defesa desses animais contra organismos invasores (Cheng e Foley, 1972; Harris, 1975; Schiliva \& Blerkom, 1981; Van der Knaap \& Loker, 1990; Locker, 1994; Bezerra et al., 1997). Alguns estudos têm procurado mostrar aspectos morfológicos e ultraestruturais dessas células com base em estudos citoquímicos (Faulk et al., 1973; Sapp \& Loker, 2000), outros trabalhos têm estudado in vitro a morfologia celular no momento do processo de encapsulamento do parasita (Hohl, 1965; Ritkin et al., 1969; Loker et al., 1982; Van Der, 1990; Sapp \& Loker, 2000). Entretanto, poucos trabalhos mostram a caracterização ultraestrutural de suas células como parte importante para o estudo de suas funçôes (Barracco et al., 1993; Motta et al., 1997; Matricon-Gondran \& Letocart, 1999). Neste trabalho, mostramos os resultados da fixação celular pelo método de rotina, no qual foi usado o tampão PHEM, cuja propriedade de preservação do citoesqueleto celular proporcionou bons resultados a esses tipos celulares. Aspectos morfológicos de estruturas citoplasmáticas foram evidenciados por meio da microscopia eletrônica de transmissão (MET), ressaltando-se os tipos de grânulos (vesículas digestivas) que caracteriza os granulócitos. Para este estudo foram usados, pela primeira vez, os hemócitos de espécimes de Biomphalaria glabrata Say (1818), da região amazônica brasileira.

\section{MATERIAL E MÉTODOS}

\section{MOLUSCOS UTILIZADOS}

Foram utilizados 90 caramujos Biomphalaria glabrata não infectados, com diâmetro de concha variando de 1,5 a $2,2 \mathrm{~cm}$, colonizados em laboratório, a partir de desovas de caramujos coletados na região Bragantina, localizada a oeste do estado do Pará.

\section{COLETA DA HEMOLINFA}

A retirada da hemolinfa foi realizada com a introdução de uma agulha $(30 \times 8,21 G 11 / 4)$ na região cefalopodal do caramujo até atingir a cavidade do manto. A retirada da agulha e a retração do animal para dentro da concha permitem a saída da hemolinfa do caramujo e o acúmulo desta na curvatura da concha, de onde o líquido é aspirado com uma seringa siliconizada. $\mathrm{O}$ volume de hemolinfa colhido de cada caramujo variou de 50 a $100 \mu \mathrm{l}$, e o volume final foi de 15 $\mathrm{ml}$. A hemolinfa foi aos poucos transferida para um tubo de vidro siliconizado mantido em baixa temperatura $\left(4^{\circ} \mathrm{C}\right)$. Após a coleta, foi centrifugada a $56 \mathrm{G}$ durante 15 minutos.

TÉCNICA DE ROTINA PARA OBSERVAÇÃO DE ULTRAESTRUTURAS CELULARES
Após centrifugação e retirada da hemolinfa, as células foram colocadas em solução fixadora por 2 horas contendo: glutaraldeído $2,5 \%$, formaldeído nascente $4 \%$, cloreto de cálcio $5 \mathrm{mM}$ em tampão PHEM (PIPES $60 \mathrm{mM}$, HEPES 20 $\mathrm{mM}$, EGTA $10 \mathrm{mM}$, KCL $70 \mathrm{mM}, \mathrm{MgCL}_{2} 5 \mathrm{mM}$ ) (Tripp, 1970), $\mathrm{pH} 7,2$. Ao retirar o fixador, foram realizadas três lavagens por 10 minutos cada, em tampão cacodilato $0,1 \mathrm{M}$ e pH 7,2. Para melhor preservação das estruturas celulares foi feito a pós-fixação em solução e tetróxido de ósmio a $1 \%$, contendo ferrocianeto de potássio $0,8 \%, 5 \mathrm{mM}$ de cloreto de cálcio em tampão cacodilato $0,1 \mathrm{M} \mathrm{e} \mathrm{pH} 7,2$ por 60 minutos a $4^{\circ} \mathrm{C}$, na ausência de luz. Para retirar o tetróxido de ósmio e demais substâncias, foram feitas três lavagens por 10 minutos cada em tampão cacodilato $0,1 \mathrm{M}$ e pH 7,2 contendo $5 \%$ de sacarose. A etapa de diafanização em bloco foi realizada com acetato de uranila a $2,5 \%$ em acetona a $25 \%$ por 60 minutos à temperatura ambiente, na ausência de luz. Para desidratação foi usada uma bateria de acetona nas concentraçôes de $50 \%$, $70 \%$ e $90 \%$ por 5 minutos em cada etapa, e depois acetona $100 \%$, em 3 etapas de 5 minutos. Para a infiltração em resina foi usada uma mistura de Epon/acetona 100\%, na proporção de $1: 1$ por 12 a 24 horas, seguida por 12 a 24 horas de infiltração em Epon puro. Para a inclusão celular foi usada Epon mais DMP-30 na estufa $60^{\circ} \mathrm{C}$ por 48 horas. Finalmente, os blocos contendo o material foram cortados em fatias com $70 \mathrm{~nm}$ de espessura e montados em grades (300 mesh). Esse material foi contrastado em acetato de uranila, lavado, e depois com citrato de chumbo, lavado novamente em água destilada, para finalmente ser examinado em MET ZEISS, 80 kV (Tripp, 1970).

\section{RESULTADOS}

Foram observadas células e estruturas celulares bem preservadas. A Figura 1 (X 19.000) mostra uma célula com características de um hialinócito, ou seja, uma célula pequena (cerca de $10 \mu \mathrm{m}$ de diâmetro), onde o núcleo ocupa quase que totalmente o citoplasma, no qual existem apenas mitocôndrias (mit), retículos endoplasmático (ret) e aparelho de Golgi (G, seta), localizados basicamente em um determinado pólo celular (seta e cabeça de seta). No núcleo $(\mathrm{N})$, existe uma massa compacta de cromatina e a presença de nucléolos (n, seta). A Figura 2 (X 11.000) mostra uma célula com características de um granulócito, ou seja, uma célula grande (cerca de 50 $\mu \mathrm{m}$ de diâmetro) onde o núcleo é bem menor em relação à célula anterior e proporcional ao citoplasma. No citoplasma se observa grande quantidade de grânulos e organelas, como mostrados nas fotos. 


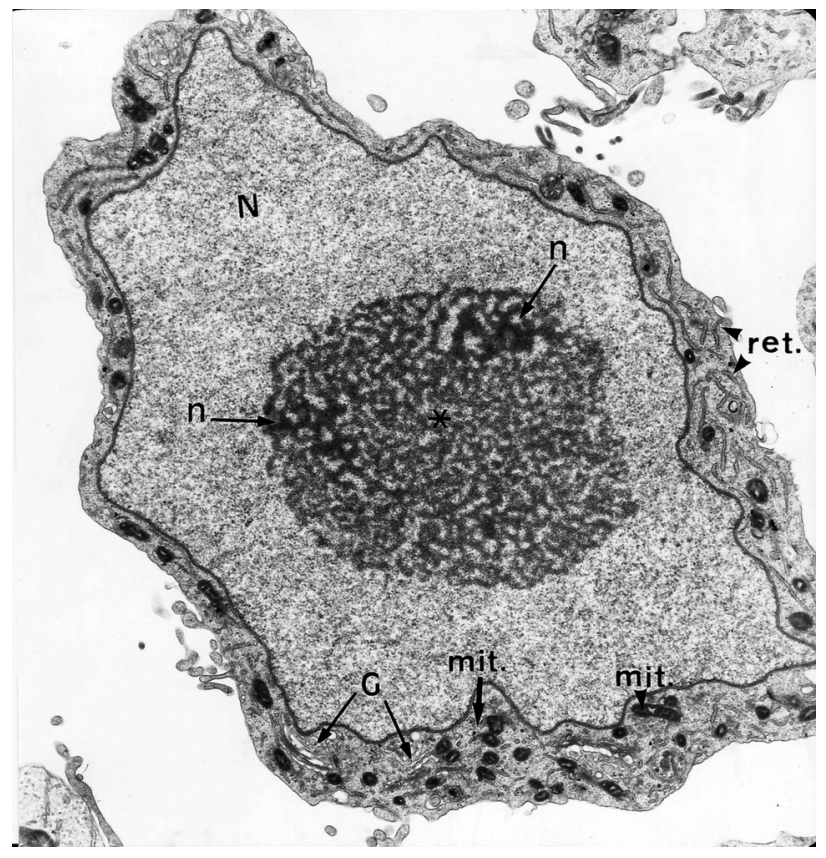

Figura 1 (X 19.000) - Hemócito (hialinócito) retirado da hemolinfa de $B$. glabrata, fixado com o tampão PHEM e observado ao MET modelo ZEISS 80 KV. Núcleo (N) com cromatina condensada $\left(^{*}\right)$ e nucléolos (n-seta). Presença de muitas mitocôndrias espalhadas por todo o citoplasma (mit.). Retículos endoplasmáticos (ret.) presentes também em grande quantidade. Aparelho de Golgi (G-seta) localizados em um determinado pólo celular.

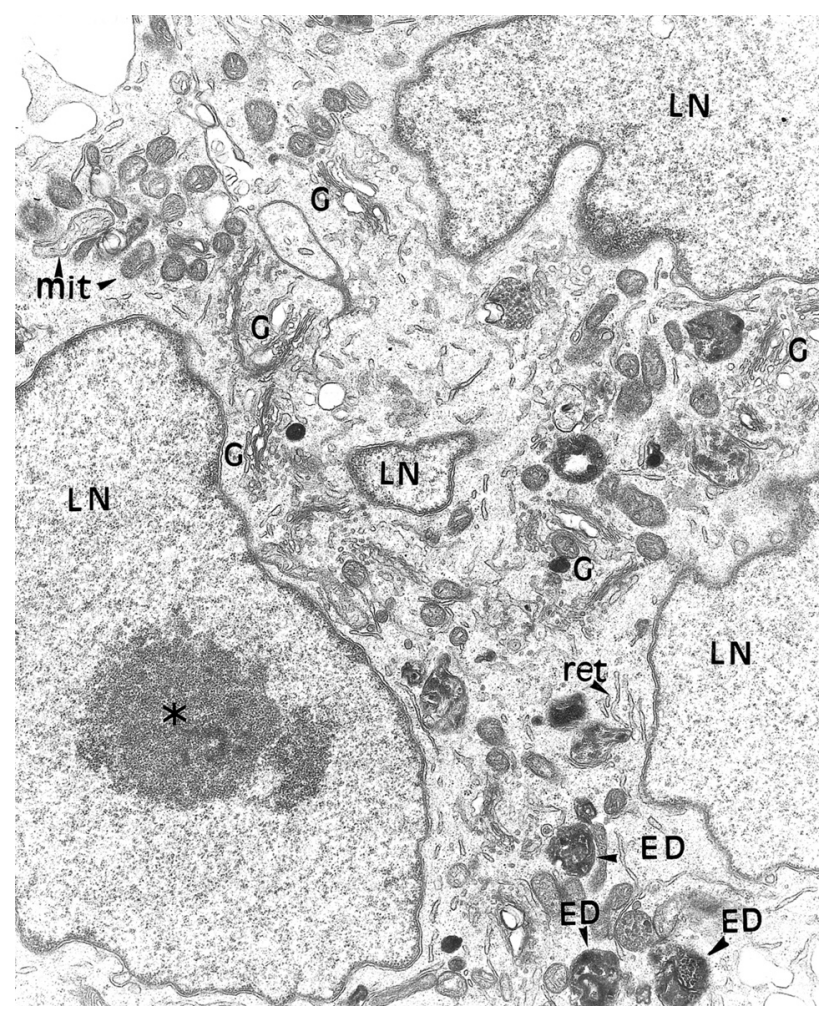

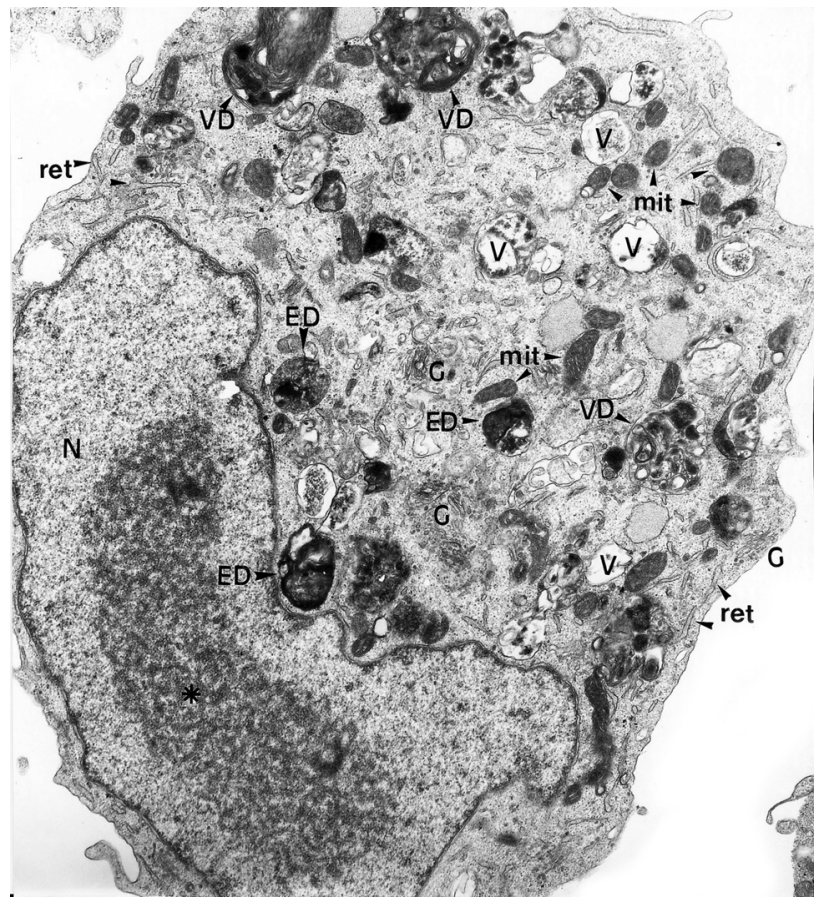

Figura 2 (X 10.000) - Micrografia eletrônica de transmissão de um hemócito (granulócito) de $B$. glabrata, processado para rotina e fixado com tampão PHEM. Observa-se uma célula com cerca de $50 \mu \mathrm{m}$ de diâmetro (bem maior em relação ao hialinócito). Núcleo (N) de formato alongado e localizado na periferia celular com cromatina $\left({ }^{*}\right)$ disposta longitudinalmente no centro do núcleo. Citoplasma rico em organelas tais como: Vesículas digestivas (VD), apresentando diferentes aspectos morfológicos; aparelho de Golgi (G) no centro e periferia celular; mitocôndrias (mit); retículo endoplasmático (ret); vesículas eletrodensas (ED) e vacúolos (V).

Entre essas organelas, observam-se grânulos com aspecto de vesículas digestivas (VD), mitocôndrias (mit), retículos endoplasmáticos (ret), aparelho de Golgi $(\mathrm{G})$ e vacúolos (V), como resultado do processo de uma digestão celular e vesículas eletrodensas (VD). O núcleo (N) mostra-se deslocado para a periferia da célula, apresentando cromatina acompanhando a forma do núcleo. Na Figura 3 (X 18.000) é mostrada a região central de um granulócito, cuja fixação celular foi possível observar: núcleo com vários lóbulos nucleares (LN) e cromatina, mitocôndrias (mit), grande quantidade de aparelho de Golgi $(G)$ na região central do citoplasma

Figura 3 (X 18.000) - Micrografia eletrônica de transmissão de um hemócito (granulócito) de B. glabrata, processado para rotina e fixado com tampão PHEM. Nesta figura, observa-se a região central de um granulócito. 0 núcleo aparece sob a forma de lóbulos nucleares ( $(\mathrm{LN})$ e a cromatina $\left({ }^{*}\right)$ condensada aparece apenas no lóbulo de maior tamanho; mitocôndrias (mit) distribuídas por todo o citoplasma; observar também a grande concentração de aparelhos de Golgi (G) no centro da célula; vesículas eletrodensas (ED) na parte central e inferior da foto. 


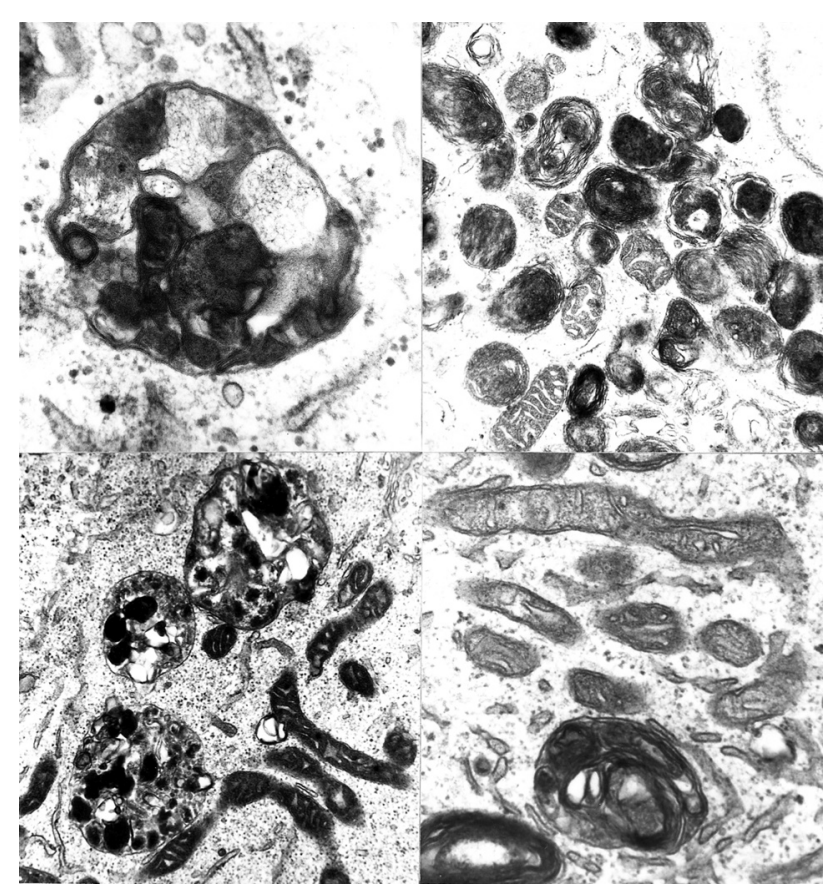

Figura 4 (X 40.000) - Micrografias eletrônicas de transmissão de hemócitos (granulócitos) de B. glabrata processados para rotina e fixados com tampão PHEM. Em vários planos, são observadas vesículas digestivas (VD) com nítidas formações membranosas, próximas de mitocôndrias (mit). É nítida também a formação de vacúolos no interior desses grânulos citoplasmáticos membranosos.

e, na região periférica (o que não é comum), grânulos sob a forma de vesículas eletrodensas. Na Figura 4 (X 40.000), apresentada em quatro planos, podem ser evidenciados a formação de vesículas digestivas membranosas e também o surgimento de vacúolos no interior destes; observou-se que, morfologicamente, eles são formados por membranas. Essas estruturas membranosas são observadas na Figura 5 (X 110.000), cujo aumento obtido possibilitou a visualização do aspecto trilaminar das mesmas.

\section{DISCUSSÃO}

O estudo morfológico dos hemócitos de B. glabrata, através de MET, não possibilita a distinção com exatidão dos tipos celulares existentes, porque as observaçōes são realizadas com base em fatias celulares, ou seja, observamos apenas uma fatia finíssima de um todo, e que assim poderá não conter, naquele momento, todas as estruturas presentes naquela célula. Entretanto, a observação dos hemócitos através do MET é um recurso técnico importante para o estudo de aspectos morfológicos de estruturas celulares responsáveis por importantes funçōes (Barracco et al., 1993; Motta et al., 1997). Neste trabalho, foi obtida uma boa fixação dos hemócitos, após ser realizado apenas o processamento de fixação das células com o tampão PHEM. Esse tampão foi escolhido

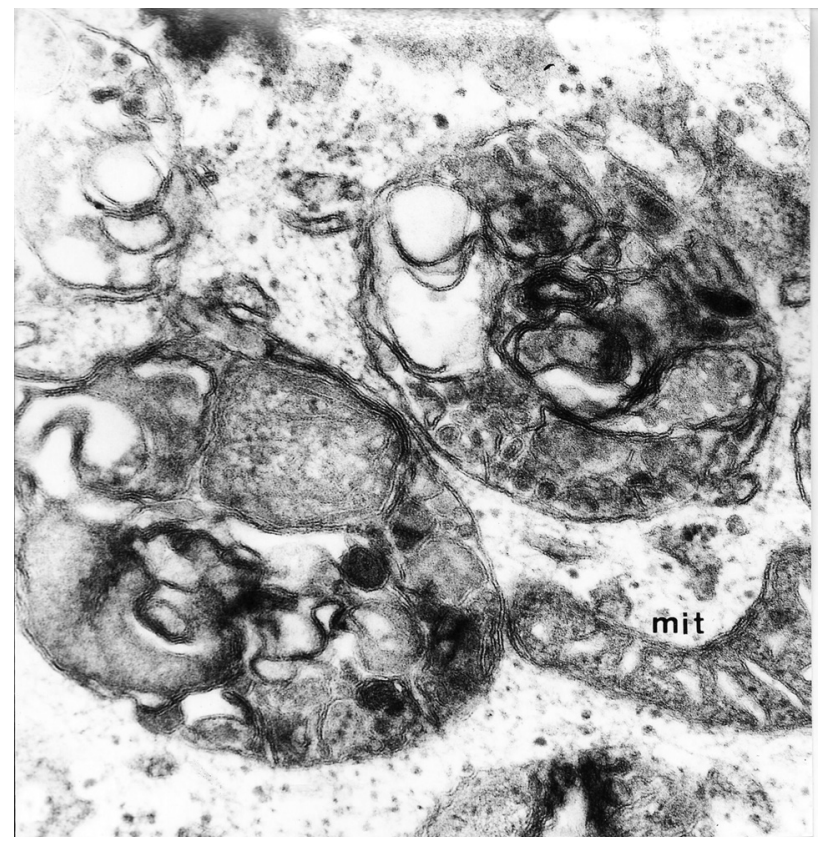

Figura 5 (X110.000) - Micrografia eletrônica de transmissão de um hemócito (granulócito) de $B$. glabrata, processado para rotina e fixado com tampão PHEM. São evidenciados dois grânulos citoplasmáticos, próximos de uma mitocôndria (mit), nos quais se observa claramente 0 aspecto trilaminar das membranas. Nota-se também o início da formação de vacúolos nessas estruturas.

por apresentar propriedades de preservação do citoesqueleto celular e também por não ter sido utilizado anteriormente em trabalhos com hemócitos de moluscos. As referências têm mostrado apenas o uso de tampão fosfato ou cacodilato (Hohl, 1965; Schliwa \& van Blerkom, 1981; Loker et al., 1982; Barracco et al., 1993; Motta et al., 1997).

As Figuras 1 e 2 são mostradas com o aumento semelhante mas, apesar disso, apresentam características morfológicas diferentes, ou seja, enquanto a primeira apresenta uma célula pequena (cerca de $10 \mu \mathrm{m}$ de diâmetro) e poucas organelas no citoplasma, a segunda apresenta uma célula maior (cerca de $50 \mu \mathrm{m}$ de diâmetro) e muitas organelas no citoplasma. Diante dessas evidências morfológicas reportamos a existência de duas células diferentes como descrito nos resultados. As numerosas mitocôndrias (mit) e vesículas digestivas (VD), mostradas nas Figuras 2 e 3, representam o aspecto ultraestrutural dos grânulos citoplasmáticos observados na microscopia óptica (Loker, 1994) para B. glabrata em diferentes estudos e também observados em microscopia eletrônica de varredura (Cheng, 1975) usando grânulos citoplasmáticos de outros moluscos, como no bivalve Crassostrea virginica. Com base em observaçôes realizadas em MET, foi questionado (Cheng, 1975) se as diferenças morfológicas observadas entre esses grânulos citoplasmáticos mostrados na Figura 4 poderiam significar diferentes atividades funcionais. Neste 
trabalho, com a fixação utilizada, foi possível observar que existem diferenças morfológicas entre esses grânulos dentro de uma mesma célula (Figura 2). Estas observações estão de acordo com trabalhos anteriormente publicados (Jeong \& Heyneman, 1976, 1984), onde foram realizados testes histoquímicos com os hemócitos de B. glabrata e observados em microscopia óptica de fase in vitro. Os resultados mostram que, em uma mesma célula, existem até três tipos de estruturas com características de vesículas digestivas. Essas estruturas formadas basicamente por membranas (Figura 4) variam de tamanho, independente do tamanho da célula as quais pertençam, ou seja, estão presentes nos cortes de células que apresentem dimensões maiores e com diferentes aspectos. Por se tratar de células de defesa, acreditamos que essas estruturas são vesículas digestivas, ligadas ao fenômeno da digestão intracelular. Formam-se quando os fagossomos fundem-se aos lisossomos com suas enzimas hidrolíticas. As vesículas grandes seriam resultantes de conglomerados de pequenos vacúolos (Figura 5). Sob esse aspecto, foi observado através dos aumentos utilizados na MET que esses grânulos parecem apresentar um crescimento dos espaços internos, do momento que são formados até o momento que estão se transformando em vacúolos. Esse provável crescimento interno dos grânulos poderia ser atribuído à produção de enzimas necessárias ao processo digestivo (Motta et al., 1997). Portanto, com a rotina utilizada e os resultados obtidos, foi possível atribuir ao tampão PHEM importante função no processo de preservação das estruturas celulares e sua contribuição para importantes estudos dessas células.

\section{BIBLIOGAFIA CITADA}

Barracco, M.A.; Steil, A.A.; Gafigios, R. 1993. Morphological characterization of the hemocytes of the pulmonate snail Biomphalaria tenagophila. Memórias Instituto Oswaldo Cruz, 88(1): 73-83.

Bezerra, F.S.; Nogueira-Machado, J.Á.; Chaves, M.M.; Martins, R.L.; Coêlho, P.M.Z. 1997. Quantification of the number and phagocytary activity of hemocytes of resistant and susceptible strains of Biomphalaria glabrata and Biomphalaria tenagophila infected with Schistosoma mansoni. Revista do Instituto de Medicina Tropical de São Paulo, 39(4) 197-201.

Cheng, T.C.; Foley, D.A. 1972. A Scanning Electron Microscope study of the cytoplasmic granules of Crassostrea virginica granulocytes. Journal of Invertebrate Pathology 20: 372-374.

Cheng, T.C.; 1975. Functional morphology and biochemistry of molluscan phagocytes. Annals of the New York Academy of Sciences, 266: 343-379.

Faulk, W.P.; Lim, K.H.; Jeong, H.; Heyneman, D.; Price, D. 1973. An approach to the study of immunity in invertebrates. In:
Braun, W.; \& Ungar, J. (Eds). Non-Specific Factors Influencing Host Resistance. Karger, Basel. p. 24-32.

Harris, K.R. 1975. The fine structure of encapsulation in Biomphalaria glabrata. Annals of the New York Academy of Sciences, 266: 446-464.

Hohl, H.R. 1965. Nature and development of membrane systems in food vacuoles of cellular slime molds predatory upon bacteria. Journal of Bacteriology, 90: 755 -765.

Jeong, K.H.; Heyneman, D. 1976. Leukocytes of Biomphalaria glabrata: morphology and behavior of granulocytic cells in vitro. Journal of Invertebrate Pathology, 28: 357-362.

Jeong, K.H.; Lie, K.J.; Heyneman, D. 1984. An ultrastructural study on ventricular encapsulation reactions in Biomphalaria glabrata exposed to irradiated echinostome parasite. International Journal for Parasitology, 14(2): 127-133.

Loker, E.S.; Bayne, C.J.; Bukley, P.M.; Kruse, K.T. 1982. Ultrastructure of encapsulation of Schistosoma mansoni mother sporacysts by hemocytes of juveniles of the 10-R2 strain of Biomphalaria glabrata. Journal of Parasitology, 68: 84-94.

Loker, E.S. 1994. On being a parasite in an invertebrate host: a short survival course. Journal of Parasitology 80: 728-747.

Matricon-Gondran, M.; Letocard, M. 1999. Internal defenses of the snail Biomphalaria glabrata I. Characterization of hemocytes and fixed phagocytes. Journal of Invertebrate Pathology, 74: 224-234.

Motta, M.C.M.; Soares, M.J.; Attias, M.; Morgado, J.; Lemos, A.P.; Saad-Nehme, J.; Meyer-Fernandes, J.R.; de Souza, W. 1997. Ultrastrutural and biochemical analysis of the relationship of Crithidia deanei with its endosymbiont. European Journal of Cell Biology, 72: 370-377.

Rifkin, E.T.; Cheng, T.C.; Hohl, H.R. 1969. An electron microscope study of the constituents of encapsulating cysts in Crassostrea virginica formed in response to Tylocephalum metacestodes. Journal of Invertebrate Pathology, 14: 211-226.

Sapp, K.K.; loker, E.S. 2000. A comparative study of mechanisms underlying digenean-snail specificity: in vitro interactions between hemocytes and digenean larvae. Journal of Parasitology, 86(5): 1020-1029.

Schliwa, M.; van Blerkom, J. 1981. Structural interaction of cytoskeletol components. Journal of Cell Biology, 90: 222 235.

Tripp, M.R. 1970. Defense mechanisms of molluscs. Journal of the Reticuloendothelial Society, 7: 173-182.

Van der Knaap, W.P.W.; Loker, E.S. 1990. Immune mechanism in trematode-snail interaction. Parasitology Today, 6: 175-182.

Recebido em 06/03/2008

Aceito em 21/05/2009 
